\title{
Las escritoras ausentes en los manuales: propuestas para su inclusión
}

\author{
Ana LÓPEZ-NAVAJAS \\ Universitat de València. Departamento de Teoría de los Lenguajes. \\ IES Vicente Gandía. Valencia \\ ana.lopez-navajas@uv.es \\ María QUEROL BATALLER \\ Universidad Católica San Vicente Mártir. Departamento de Lenguas y Literatura \\ maria.querol@ucv.es
}

Recibido: abril 2014

Aceptado: septiembre 2014

\section{RESUMEN}

El presente trabajo es consecuencia de la investigación de la Universitat de València que analizó la presencia de las mujeres en los contenidos de todas las asignaturas de la ESO en tres editoriales distintas. Se revisaron 109 manuales y los resultados que se obtuvieron fueron desastrosos: solo un 7,6 \% de los personajes citados eran mujeres (López-Navajas, 2014). En el presente trabajo se ejemplifica con dos relevantes dramaturgas, las propuestas didácticas que se están desarrollando en el marco del proyecto Las mujeres en la ESO. Estas podrían convertirse, además, en un vehículo adecuado para dar a conocer en las aulas un mayor número de voces femeninas.

Palabra clave: educación, ausencia, inclusión, dramaturgas, propuesta didáctica.

\section{Absent female writers in course books: an inclusion proposal}

\begin{abstract}
The purpose of this paper is to call attention to the results of a research which analysed the presence of women in the didactic materials used in Spanish Compulsory Secondary Education. 109 text books from three different publishers were checked and the results were very disappointed: just 7,6 \% of the names quoted were women (López-Navajas, 2014). In addition to this, in this paper two relevant female Mexican playwrights are used to exemplify the didactic proposals that are been developed within the framework of the project "Women in ESO" (Compulsory Secondary Education). Moreover, these proposals could become a suitable vehicle to publicise a greater number of voices and texts of Latin American origin, in general, and Mexican, in particular, among Spanish society.
\end{abstract}

Keywords: teaching, absence, including, playwrights, didactic proposals 
Les auteures absentes dans les manuels de clase: des propositions pour leur inclusion

\section{RÉSUMÉ}

Cet article est le résultat de la recherche de l'Université de Valence qui a analysé la présence des femmes dans les contenus de toutes les matières de l'ESO, en 109 manuels qui appartiennent à trois éditeurs différents. Les résultats obtenus étaient désastreux: seulement 7,6\% des personnages mentionnés étaient des femmes (López-Navajas, 2014). Dans ce travail nous avons illustré, avec deux importantes dramaturges, quelques approches didactiques sur littérature développées dans le cadre du projet Les femmes dans l'ESO. Ce proposition pourrait aussi devenir un véhicule approprié pour faire connaître des autres voix féminines dans les classes.

Mots-clés: l'éducation, l'absence, l'inclusion, dramaturges, approche didactique.

SUMARIO: 1. Introducción. 2. Metodología de inclusión. 3. A modo de ejemplo. 3.1. Sor Juana Inés de la Cruz. 3.1.1. Enfoque metodológico. 3.1.2. Información sobre la autora. 3.1.3. Actividades. 3.2. Elena Garro. 3.2.1. Enfoque metodológico. 3.2.2. Información escritora. 3.2.3. Actividades. 4. Conclusión. 5. Bibliografía

\section{INTRODUCCIÓN}

En torno a 1987 comenzaron a realizarse los primeros análisis sobre el sexismo en los libros de texto (Garreta y Careaga, 1987; Heras, 1987; Subirats, 1993). Estos primeros trabajos en el ámbito español centraron su atención en el lenguaje y la representación de las mujeres; en el inicio del s. XX, sin embargo, y al amparo de los estudios de mujeres que han sacado a luz innumerables contribuciones femeninas en todos los campos, el interés también se ha centrado en observar qué peso se les concede a las mujeres en los contenidos de los manuales escolares -que, recordemos, son los principales transmisores de los referentes culturales y sociales (Lomas, 2002; Blanco, 2004; Espigado, 2004; Rodríguez, 2004). En este contexto en 2009 se creó el proyecto Las mujeres en los contenidos de la ESO, cofinanciado por el Instituto de la Mujer y el Ministerio de Ciencia e Innovación. En este se analizó, de forma cuantitativa y cualitativa, la presencia de las mujeres en los contenidos de todas las asignaturas de los cuatro cursos que comprende la actual Educación Secundaria Obligatoria (ESO, en lo que sigue) en tres editoriales del ámbito español (Santillana, Oxford y SM).

Los datos que se recogieron pertenecen a todas las asignaturas obligatorias (Matemáticas, Castellano, Ciencias de la Naturaleza, Ciencias Sociales, Ética, Educación para la Ciudadanía, Educación Plástica, Música, Educación Física, Tecnologías, Francés, Inglés, Valenciano) y de oferta obligatoria (Física y Química, Biología y Geología, Informática, Tecnología, Latín) de toda la etapa de ESO en España. 
Nos centramos en la ESO por ser esta la última etapa obligatoria, lo que propicia que su influencia se extienda a toda la sociedad, y por tener entre sus objetivos finales no sólo la formación académica, sino también la formación ciudadana.

Los resultados generales de dicha investigación (López-Navajas, 2014), a disposición pública en -http://mujeresenaleso.uv.es-, demuestran que la presencia ${ }^{1}$ y/o aparición ${ }^{2}$ de referencias femeninas en estos textos es muy reducida ${ }^{3}$. La frecuencia media de aparición de personajes femeninos se sitúa en torno al 7,6 \%, si bien en materias tan relevantes para la creación de referentes y patrones sociales como la historia (materia incluida en la asignatura de CC Sociales) desciende hasta el 5\% y en las asignaturas de carácter tecnológico su ausencia es prácticamente total. Si nos centramos en la asignatura de Castellano, observamos que se repite la tendencia antes expuesta.

La cifra de presencia o aparición de mujeres es muy reducida. No queda constancia de sus logros y aportaciones en los contenidos de los manuales

Las apariciones denotan cifras significativamente inferiores a las de presencia, lo que implica una aún menor repercusión en los manuales.

Para valorar estos últimos datos, quizá sea conveniente recordar que la asignatura de Castellano se organiza en cuatro bloques de contenidos, a través de los cuales se desarrollan los objetivos y contenidos exigidos en el currículo: Comunicación, Lengua y Sociedad, Técnicas de trabajo, Conocimiento de la Lengua y Educación Literaria. El bloque de Educación Literaria es el de mayor contenido histórico, cultural y social, especialmente en los cursos de $3^{\circ}$ y $4^{\circ}$ de ESO, que es cuando se imparten los contenidos relativos a historia de la literatura. Significativamente en los materiales analizados en estos dos cursos $\left(3^{\circ}\right.$ y $\left.4^{\circ}\right)$ desciende notablemente -ver Fig. 1- la aparición de referencias femeninas (López y Querol, 2012). Las cifras de literatura muestran un panorama desolador. Desde el siglo XII al XVIII solo se cita a una escritora: Santa Teresa de Jesús. Ni a Teresa de Cartagena, Sor Juana Inés de la Cruz, María de Zayas o Mª Rosa Gálvez, por citar algunas de las imprescindibles, se las nombra. Como si no existiera tradición literaria femenina. Pero además, en el siglo XX, en dos editoriales no se cita ni a

${ }^{1}$ La presencia (p.) se utiliza como valor para cuantificar el número de personajes que aparecen en los textos. No se contabilizan ni dioses ni personajes de ficción.

${ }^{2}$ La aparición (a.) se utiliza como valor para cuantificar la recurrencia de los personajes en los textos, es decir, el número de veces que aparecen en los textos.

3 La base de datos permite obtener información de dos indicadores: el primero proporciona la cantidad y el listado de nombres de todos los personajes, hombres y mujeres, que aparecen en todas las asignaturas de la ESO; el segundo mide la repercusión que las mujeres tienen en el texto, por lo que nos muestra las veces que aparecen citados los personajes y el modo (citado, reseñado, obra original e ilustración) y el lugar (cuerpo del texto, actividades o anexo) del texto donde lo hacen. 
una sola poeta ni a una sola dramaturga, cuando ha habido cientos de ellas de gran calidad literaria. ¿Es esto realmente un panorama de la literatura del siglo XX? ¿Dónde están las escritoras? No solo está desparecida su tradición literaria sino que tampoco se cuenta con ellas cuando se presenta la literatura contemporánea (López y López, 2012). Se trata, pues, de una literatura falseada que escamotea sus propias voces.

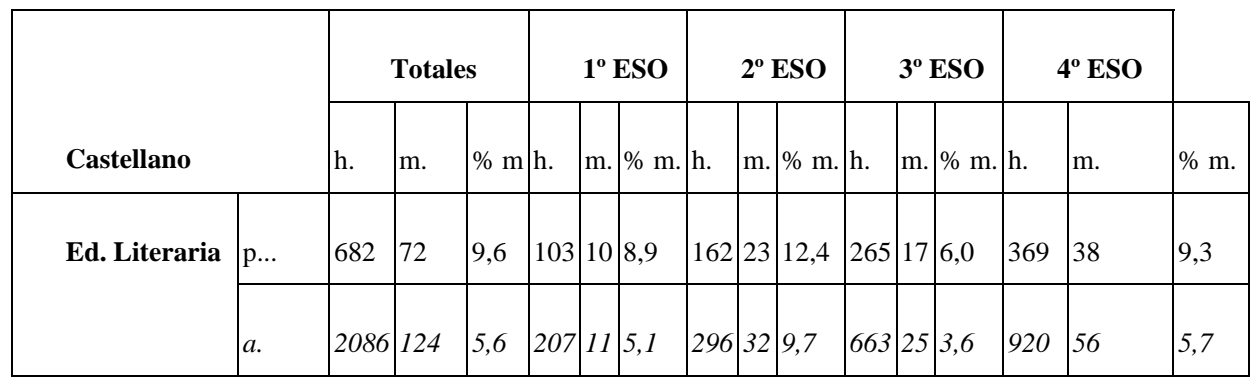

Fig 1. Personajes (p.) y apariciones (a.) en el bloque Educación Literaria de la asignatura Castellano en la ESO de hombres (h.) y mujeres (m.)

En consecuencia, pese a que los estudios de los últimos años han fundamentado con solvencia las contribuciones femeninas -no solo en la literatura (Caballé, 2004; Montejo y Baranda, 2002; Serrano y Sanz, 1975; Zavala y Díaz, 1993-2000) sino también en las ciencias (Alic, 1991; Álvarez, Nuño y Solsona, 2003; Figueiras et ál, 1998), el arte (Coll, 2001; Greer, 2005; Mayayo, 2003; Muñoz, 2004), la música (Álvarez Cañibano, 2008; Briscoe, 2004; Lorenzo, 2008; Rosselló, 1995; Sadie y Samuel, 1994) o el pensamiento (Martino y Bruzzese, 1994)- y han señalado también la importancia social que han tenido en todas las épocas a lo largo de la historia y en las diferentes materias, la realidad es que dichos referentes culturales no quedan reflejados en los materiales con los que se forma al alumnado de ESO en España. Por ello no es extraño que, ante esta constante ausencia de referencias femeninas, en el imaginario colectivo se cree la idea de que las mujeres han aportado apenas nada al desarrollo social y cultural.

Tal ausencia de reconocimiento tiene dos importantes repercusiones. En primer lugar, las relega a la consideración de ciudadanas de segunda categoría, lo que conlleva una fuerte minusvaloración social; y, en segundo lugar, representa un falseamiento de la historia y de la memoria cultural común, que denota una importante falta de rigor en el relato que proporciona la propia educación obligatoria. Por otra parte, la exclusión de las mujeres del discurso que se transmite en los contenidos educativos no solo supone una falta de rigor inadmisible para una etapa educativa de esa importancia, sino que infringe la propia ley educativa, contraviniendo sus fines y objetivos. A título de ejemplo podemos señalar como la 
situación antes descrita contradice dos de los fines promulgados en el Real Decreto 1631/2006 y la actual LOMCE, que en relación a fines y objetivos no ha cambiado. Contraviene el fin académico, al transmitir un relato histórico falseado y unos contenidos faltos de rigor académico, y también el referido a la formación ciudadana, al convertirse en un instrumento de transmisión de desigualdades.

\section{Artículo 3. Finalidad}

la finalidad de la educación secundaria obligatoria consiste en lograr que el alumnado adquiera los elementos básicos de la cultura, especialmente, en sus aspectos humanístico, artístico, científico y tecnológico; que desarrolle y consolide hábitos de estudio y de trabajo; preparar al alumnado para su incorporación a estudios posteriores y para su inserción laboral, y formarlo para el ejercicio de sus derechos y obligaciones en la vida como ciudadanas y ciudadanos.

Con el fin de corregir y subsanar estas severas carencias observadas en la actual realidad educativa española, se está desarrollando un segundo proyecto, Las mujeres en la ESO. El objetivo de este nuevo proyecto es crear un instrumento de intervención didáctica dentro del aula, en este caso una web, que facilite la inclusión real de las mujeres en los contenidos que estudia el alumnado en el nivel de ESO en España y que permita romper la impermeabilidad que muestran los contenidos a la inclusión de las aportaciones femeninas.

Dicho todo esto, en el presente trabajo se concreta una parte de la propuesta didáctica de inclusión de escritoras que se está desarrollando en el marco del nuevo proyecto. En este caso, se presentan las fichas de dos dramaturgas cuyas actividades, a partir de textos, se pueden utilizar tanto para estudiar géneros literarios, figuras o temas, así como para ilustrar un periodo literario determinado o para trabajar el oral (con poesía).

\section{METODOLOGÍA DE INCLUSIÓN}

La presencia y la participación de las mujeres (científicas, músicas, artistas...) en el desarrollo histórico está ya muy documentado gracias a los estudios de mujeres que se han llevado a cabo a lo largo de los últimos años. En la literatura, una de las áreas donde la participación femenina ha sido más fecunda, nos encontramos con autoras a las que no solo se les reconoce una gran calidad literaria, sino que en su momento gozaron también de un notable éxito y reconocimiento por parte de sus coetáneos como, por ejemplo, se evidencia en el texto de Lope de Vega El laurel de Apolo. Sin embargo, como ya se demostró en la investigación antes citada, estas

${ }^{4}$ La actual ley educativa se basa en lo establecido en dicho decreto, en el cual se explicitan los fines, objetivos y contenidos de las enseñanzas mínimas correspondientes a la ESO. 
mujeres apenas son referidas en los libros de texto que se utilizan para formar al alumnado de ESO. Así pues, resulta evidente la necesidad de incorporar un mayor número de figuras femeninas en la enseñanza de la literatura, y en el marco de dicha necesidad se incluye el proyecto del que nace este trabajo.

La metodología que se ha empleado para la inclusión de las literatas -o de todas aquellas mujeres que están sujetas a una tradición histórica como pintoras, artistas, músicas o pensadoras y activistas- en los contenidos está supeditada a uno de los presupuestos teóricos de los que parte el proyecto. Según este, aunque muy habitualmente se ha tendido a considerarlas como excepcionales ${ }^{5}$, en la medida que las aportaciones de las mujeres forman parte del relato social y cultural, sus referencias no deben tratarse así, sino dentro de una continuidad en el tiempo y con pleno protagonismo. En consecuencia, no solo se rechazan epígrafes como "La mujer en el Romanticismo" o "La mujer en la Edad Media", sino que en las actividades propuestas y en el relato de la época todas las mujeres deben citarse en relación a las circunstancias históricas y sociales que las rodean, o como pertenecientes a un movimiento artístico o como coetáneas, o en relación a los conceptos y géneros que hayan trabajado. De cada época se debe conocer el trabajo y las aportaciones diferenciadas que mujeres y hombres han realizado en ella, debe quedar constancia de lo que unas y otros han realizado y de esta forma ir trazando la memoria cultural colectiva. Por eso una de las mejores propuestas se deriva de trabajar directamente con su obra (en esta caso literaria, pero en otras materias será obra musical o pictórica o científica)

Una vez aclarada esta premisa, en las siguientes líneas se especifica la forma y modo en que dichas referencias se incluyen en la mencionada web, y que, dada la temática de este trabajo, se limitará a la asignatura de Castellano. Así pues, la necesaria inclusión de las referencias femeninas se hará a partir de los siguientes elementos:

a) El enfoque didáctico, que proporciona las indicaciones que justifican la inclusión de la referencia, así como la forma y el modo en que estas deben aparecer. En el caso concreto de las literatas no solo se debe realizar su inclusión, sino también situarlas y estudiarlas en un contexto histórico y literario.

b) La información sobre la autora. Dicha información incluye la realización de una ficha, en la que se indican datos como nombre, apellidos, alias, fecha de nacimiento, fecha de defunción y nacionalidad; una breve reseña, que contiene la información básica y esencial para la adecuada identificación de la autora por parte del alumnado, una biografía, cuyo

${ }^{5}$ Una importante consecuencia de tal actuación ha sido que habitualmente estas no han sido incluidas en los cánones literarios. 
carácter más extenso permite especificar algunas singularidades de su obra y producción; y, finalmente, alguna referencia bibliográfica o webgráfica, con la que sea posible ampliar la información sobre esta autora o su obra.

c) Las actividades. Estas han sido propuestas por los colaboradores del proyecto y están vinculadas a la consecución y asimilación de los objetivos y contenidos propuestos en el actual currículo de ESO. En consecuencia, las actividades siempre son enmarcadas en un nivel, asignatura y bloque temático. Además incluyen las competencias básicas que son trabajadas en ellas. Dependiendo de la accesibilidad y la adecuación del material con el que se cuente, las actividades pueden tener la propia obra, o fragmentos de esta, como elemento de estudio, o también se puede recurrir a su cita o referencia intertextual. Las actividades propuestas se realizan desde una perspectiva abierta, por lo que el docente puede, en función del contexto de aprendizaje, seleccionar aquellas actividades o aquellas secciones que considere más adecuadas.

\section{A MODO DE EJEMPLO}

La propuesta que presentamos a continuación consiste en una serie de propuestas didácticas de lengua y literatura que, como todas, están inscritas en un curso (en este caso será $2^{\circ}, 3^{\circ}$ y $4^{\circ}$ de ESO), y en un bloque temático, por lo que se puede incluir directamente en el aula, es decir, cuando se trabaje el teatro barroco en $3^{\circ}$ de ESO se puede utilizar parte o toda la actividad propuesta, en la unidad didáctica o el manual que se esté utilizando ${ }^{6}$. Pero a la vez sirven de modelo para ejemplarizar de qué manera -a través de sus textos y su obra- se debe incluir la producción literaria femenina en los manuales.

Debemos ser conscientes de que existe una tradición literaria femenina constante y rica, que se está omitiendo y que pertenece al acervo cultural no solo de las mujeres, sino de los hombres también. Incluirlas y reescribir un relato de la literatura que de cuenta de las voces de mujeres y hombres, con su producción diferenciada es responsabilidad que compete directamente a las profesoras y profesores y que compromete también su rigor académico, su nivel profesional. Una literatura donde no se reconozca la voz a las escritoras es una literatura sesgada, adulterada, amputada. Así, la formación del profesorado a este respecto se convierte en una necesidad.

Hemos seleccionado dos dramaturgas, puesto que es un género del que no aparecen autoras en los manuales: Sor Juana Inés de la Cruz, escritora novohispana

\footnotetext{
${ }^{6}$ Para la realización de las propuestas didácticas se han tomado como referencia las directrices establecidas en el Real Decreto 1631/2006 y el Decreto 112/2007.
} 
del Barroco español en su producción dramática y Elena Garro, escritora mejicana del s. XX, porque la presencia de escritoras latinoamericanas es nula.

A partir de sus textos se han propuesto una serie de actividades que se pueden incluir en diversos temas de lengua y literatura de $2^{\circ}, 3^{\circ}$ y $4^{\circ}$ de ESO.

Un problema añadido para el estudio de la obra de algunas escritoras es que tal y como afirman Gutiérrez y Prado (2006: 9-10), se localizan al margen del canon, sus textos son de difícil acceso, no suelen ser reeditadas o su difusión y distribución es insuficiente ${ }^{7}$. Las escasas obras que se pueden encontrar y el nada fácil acceso a ellas se convierte en un escollo para el conocimiento y la divulgación de estas escritoras, pues si no podemos leerlas, no podemos conocerlas. En consecuencia, parece evidente que para dar a conocer y hacer visibles a nuestras escritoras, tanto en la enseñanza de la literatura en los centros escolares como para el público en general, resulta imprescindible disponer de la edición de sus obras -ya sea en ediciones críticas, en formatos divulgativos o en adaptaciones adecuadas para su lectura en institutos y colegios. Además, señalan Gutiérrez y Prado (2006: 9-10), el público en general solo las vincula con uno o dos trabajos concretos enmarcados dentro de obras temáticas muy específicas o géneros literarios muy específicos. El caso de Sor Juana Inés es muy evidente, pues tradicionalmente su obra se vincula a la tradición lírica, -aunque ni siquiera ella aparece en los currículos y materiales escolares analizados-; en cambio, poco o ninguna referencia aparece a su prolífica producción teatral, como por ejemplo, sus tres autos sacramentales, comedias, loas o villancicos. En otros casos, como por ejemplo, Elena Garro, su obra suele ser referida en relación con el que fue su marido, Octavio Paz, y a su "enfrentamiento con el medio cultural mexicano".

Dicho todo esto, seguidamente mostramos, a modo de ejemplo, las fichas que referidas a dichas autoras se podrán encontrar en la web del proyecto Las mujeres en la ESO. Como se verá, las fichas siempre deben contener los apartados de: enfoque metodológico, información sobre la autora- que a su vez incluye ficha, reseña, biografía y webgrafía- y actividades.

\subsection{Sor Juana Inés de la Cruz}

\subsubsection{Enfoque metodológico}

Entre los escritores del Barroco destaca notablemente la figura de Sor Juana Inés de la Cruz, que posiblemente represente una de las cumbres del Siglo de Oro español y que cultivó con gran acierto la poesía y el teatro. Se trata, por tanto, de un nombre de obligada presencia en el curso de $3^{\circ} \mathrm{ESO}$, momento en el que se estudia

${ }^{7}$ En López y Querol (2012) se puso de manifiesto las limitaciones de la divulgación editorial, puesto que la obra de la mayor parte de escritoras, salvo un grupo de escritoras consolidadas, resulta de muy difícil acceso. 
específicamente este periodo literario, el Barroco, y géneros como los autos sacramentales, la comedia o la poesía alegórica.

Además, la obra de Sor Juana resulta ampliamente conocida por su firme postura al reivindicar las posibilidades y el derecho de las mujeres a escribir y educarse, tal y como manifiesta en su Respuesta a Sor Filotea de la Cruz. Postura que también defiende en dos de sus dramas, Los empeños de una casa y Amor es más laberinto, en los que ofrece una particular visión de la mujer en consonancia con el parecer que en España tenían autoras como María de Zayas y Ana Caro Mallén de Soto. Por ello, sus textos y su referencia resultan extremadamente pertinentes para conocer la literatura de la época.

\subsubsection{Información sobre la autora}

\subsubsection{Ficha}

Alias: Sor Juana Inés de la Cruz

Apellidos: Asbaje y Ramírez

Nombre: Juana de

Fecha de nacimiento: 12/11/1651

Fecha de defunción: 17/04/1695

Nacionalidad: novohispana

\subsubsection{Reseña}

Juana de Asbaje y Ramírez, más conocida como Sor Juana Inés de la Cruz, fue una de los grandes escritores que dio el Siglo de Oro español. La mayor parte de su obra son poemas- líricos y alegóricos- y dramas- religiosos y profanos-; si bien uno de sus escritos en prosa, La repuesta a Sor Filotea de la Cruz es una de sus obras más conocidas.

\subsubsection{Biografía}

Sor Juana Inés de la Cruz, cuyo verdadero nombre fue Juana de Asbaje y Ramírez, nació el 12 de noviembre de 1651 en México y murió, también en México, el 17 de abril de 1695 como consecuencia de una epidemia.

Juana era hija ilegítima de una criolla y de un militar español. Se hizo religiosa en 1967, primero en la Orden de las Carmelitas Descalzas y más tarde (1669) en las Jerónimas.

Destaca como poeta, aunque su producción literaria abarca, también, el teatro y la prosa.

Como poeta, Primero sueño, un largo poema sobre el conocimiento, es su contribución más genuina. Además, tanto sus sonetos líricos como su poesía satírica destacan por su afinado lirismo y su agudeza, por lo que se convirtieron en referentes de la época.

La respuesta a Sor Filotea de la Cruz es una epístola en respuesta a Sor Filotea de la Cruz. En realidad bajo este nombre se encuentra el obispo de Puebla, que 
recrimina a Sor Juana las opiniones vertidas en la Carta Atenagórica. Se trata de una de las obras más conocidas de Sor Juana y también una de las que mayor controversia suscitó en el momento por las opiniones que defendía: el derecho de la mujer a expresarse libremente y a la educación. Lo que la convierte en una de los escritores que participaron en la "querelle des femmes", debate que se extendió hasta bien entrado el siglo XVIII y que, desde diversos enfoques, trató sobre el derecho de las mujeres a la educación y al estudio.

Sor Juana Inés es también autora de algunas composiciones musicales.

\subsubsection{Webgrafía}

Sor Juana Inés de la Cruz, [http://www.cervantesvirtual.com/bib_autor/Sorjuana/, consulta 25/09/2012]

\subsubsection{Actividades.}

3.1.3.1 ACTIVIDAD. ALEGORÍAS EN EL DIVINO NARCISO DE Sor Juana Inés De La Cruz

NIVEL: $3^{\circ}$ ESO

BLOQUE DE CONTENIDOS: Educación Literaria- Teatro Barroco- Autos Sacramentales

COMPETENCIAS BÁSICAS: 1. Competencia en comunicación lingüística; 4. Tratamiento de la información; 6. Competencia cultural y artística; 7. Competencia para aprender a aprender

PROPUESTA DIDÁCTICA:

1- Lee con atención el siguiente fragmento del auto sacramental El divino Narciso de Sor Juana Inés de la Cruz.

\section{ESCENA XV}

(Sale la Gracia.)

GRACIA

NATURALEZA HUMANA

GRACIA
Ninfa bella, ¿por qué lloras tan tiernamente? ¿Qué en este sitio buscas ¿Qué pena es la que sientes? Busco a mi dueño amado; ignoro dónde ausente lo ocultan de mis ojos los hados inclementes. ¡Vivo está tu Narciso; no llores, no lamentes, ni entre los muertos busques al que está vivo siempre!» 


\section{ESCENA XVI}

(Sale Narciso, con otras galas, como resucitado, por detrás de la Naturaleza; y ella se vuelve a mirarlo.)

\begin{tabular}{|c|c|}
\hline NARCISO & $\begin{array}{l}\text { ¿Por qué lloras, pastora? } \\
\text { Que las perlas que viertes } \\
\text { el corazón me ablandan, } \\
\text { el alma me enternecen. }\end{array}$ \\
\hline $\begin{array}{l}\text { NATURALEZA } \\
\text { HUMANA }\end{array}$ & $\begin{array}{l}\text { Por mi Narciso lloro, } \\
\text { señor; si tú Le tienes, } \\
\text { dime dónde está, } \\
\text { para que yo vaya a traerle. }\end{array}$ \\
\hline NARCISO & $\begin{array}{l}\text { ¿Pues cómo, esposa mía, } \\
\text { no puedes conocerme, } \\
\text { si a mi beldad divina } \\
\text { ninguna se parece? }\end{array}$ \\
\hline $\begin{array}{l}\text { NATURALEZA } \\
\text { HUMANA }\end{array}$ & $\begin{array}{l}\text { ¡Ay, adorado esposo, } \\
\text { deja que alegremente } \\
\text { llegue a besar tus plantas! }\end{array}$ \\
\hline NARCISO & $\begin{array}{l}\text { A tocarme no llegues, } \\
\text { porque voy con mi padre } \\
\text { a su trono celeste. }\end{array}$ \\
\hline $\begin{array}{l}\text { NATURALEZA } \\
\text { HUMANA }\end{array}$ & $\begin{array}{l}\text { Luego, ¿̇me dejas sola? } \\
\text { ¡Ay, Señor, no me dejes; } \\
\text { que volverá a insidiarme } \\
\text { mi enemiga serpiente! }\end{array}$ \\
\hline
\end{tabular}

Sor Juana Inés de la Cruz, EL divino Narciso
A) Comprensión léxica

A.1) Busca un sinónimo en el texto para los siguientes términos:

Belleza:

Engañarme:

A.2) Explica la metáfora del verso 1859. ¿A qué término sustituye la palabra "perlas”? ¿Cuál crees que es la semejanza que existe entre ambos términos?

B) Comprensión global

B.1) Señala los personajes que intervienen en este fragmento

B.2) ¿Por qué llora Naturaleza Humana?

B.3) ¿Qué le ha ocurrido a Narciso?

C) Contenidos literarios: Autos Sacramentales

C.1) A partir del texto ejemplifica las características más significativas de los autos sacramentales:

Obras de teatro 
Personajes alegóricos

Tema religioso

Carácter didáctico

C.2) En el Barroco hay otras autoras y autores muy conocidos por sus autos sacramentales. Nombra a una o uno de ellos y alguna de sus obras más conocidas.

\subsubsection{ACTIVIDAD. TEATRO BARROCO. EL SUCESO DE DOÑA ANA} EN LOS EMPEÑOS DE UNA CASA. Sor Juana Inés de la Cruz

NIVEL: $3^{\circ}$ ESO

BLOQUE DE CONTENIDOS: Educación Literaria. El teatro barroco

COMPETENCIAS BÁSICAS: 1. Competencia en comunicación lingüística; 4. Tratamiento de la información; 5. Competencia social y ciudadana; 6 . Competencia cultural y artística; 7. Competencia para aprender a aprender

PROPUESTA DIDÁCTICA:

1-Lee con atención el siguiente fragmento dramático de Los empeños de una casa de Sor Juana Inés de la Cruz.

Doña Ana:

Pero es preciso al informe

que de mis sucesos hago

—aunque pase la modestia

la vergüenza de contarlo-,

para que entiendas la historia,

presuponer asentado

que mi discreción la causa

fue principal de mi daño.

Inclinéme a los estudios

desde mis primeros años

con tan ardientes desvelos

con tan ansiosos cuidados,

que reduje a tiempo breve

fatigas de mucho espacio

$[\ldots]$
Era de mi patria toda

el objeto venerado

de aquellas adoraciones

que forma el común aplauso;

y como lo que decía.

[...]

La pasión se puso anteojos

de tan engañosos grados,

que a mis moderadas prendas

agrandaban los tamaños.

[...]

Entre estos aplausos yo,

con la atención zozobrando

entre tanta muchedumbre, sin hallar seguro blanco, 
no acertaba a amar a alguno, viéndome amada de tantos. Sin temor en los concursos defendía mi recato con peligros del peligro y con el daño del daño [...]..

Y como tan neciamente conmigo se descuidaron, fue preciso hallarme el riesgo donde me perdió el cuidado. Sucedió, pues, que entre muchos

que de mi fama incitados contestar con mi persona intentaban mis aplausos llegó acaso a verme - $\mathrm{iAy}$ cielos!,

¿Cómo permitís tiranos

que un afecto tan preciso se forjase de un acaso?don Carlos de Olmedo, un joven forastero, mas tan claro por su origen, que en cualquiera lugar que llegue a hospedarlo, podrá no ser conocido, pero no ser ignorado. [...]

Gozaba un entendimiento tan sutil, tan elevado, que la edad de lo entendido era un mentís de sus años

[...]

En fin, yo le amé; no quiero cansar tu atención contando de mi temerario empeño la historia caso por caso; [...]

Creció el amor en los dos recíproco y deseando que nuestra feliz unión lograda en tálamo casto confirmase de Himeneo el indisoluble lazo; y porque acaso mi padre, que ya para darme estado andaba entre mis amantes los méritos regulando, atento a otras conveniencias no nos fuese de embarazo, dispusimos esta noche la fuga, y atropellando el cariño de mi padre, y de mi honor el recato,

salí a la calle, y apenas daba los primeros pasos entre cobardes recelos de mi desdicha, fïando la una mano a las basquiñas 
y a mi manto la otra mano, cuando a nosotros resueltos llegaron dos embozados. "¿Qué gente?" dicen, y yo con el aliento turbado,..

sin reparar lo que hacía porque suele en tales casos hacer publicar secretos el cuidado de guardarlos-, "¡Ay, Carlos, perdidos somos!" dije, y apenas tocaron mis voces a sus oídos cuando los dos arrancando los aceros, dijo el uno: "¡Matadlo, don Juan, matadlo;

que esa tirana que lleva, es doña Leonor de Castro, mi prima." Sacó mi amante el acero, y alentado, apenas con una punta llegó al pecho del contrario, cuando diciendo: "¡Ay de mí!" dio en tierra, y viendo el fracaso dio voces el compañero, a cuyo estruendo llegaron

algunos; y aunque pudiera la fuga salvar a Carlos, por no dejarme en el riesgo se detuvo temerario, de modo que la justicia, que acaso andaba rondando, llegó a nosotros, y aunque segunda vez obstinado intentaba defenderse, persuadido de mi llanto

rindió la espada a mi ruego, mucho más que a sus contrarios. Prendiéronle, en fin; y a mí, como a ocasión del estrago, viendo que el que queda muerto era don Diego de Castro, mi primo, en tu noble casa, señora, depositaron mi persona y mis desdichas, donde en un punto me hallo

sin crédito, sin honor, sin consuelo, sin descanso, sin aliento, sin alivio, y finalmente esperando la ejecución de mi muerte en la sentencia de Carlos. 
Sor Juana Inés de la Cruz, Los empeños de una casa.

A) Comprensión global

A.1) Contesta las siguientes preguntas sobre el texto:

Describe lo que le ha ocurrido doña Ana.

¿Por qué cosas siente inclinación doña Ana?

¿Por qué doña Ana es pretendida por varios hombres? ¿Qué fama tiene?

¿Cuál fue "la causa principal de su daño"?

¿Por qué crees que dice eso? Explícalo detalladamente.

¿Qué es lo que le gusta de don Carlos?

¿Por qué decidieron fugarse?

B) Análisis de la forma

B.1) Señala el fragmento del texto donde ella dice cómo se siente tras lo sucedido y di qué figura emplea para dar mayor intensidad a su sentimiento.

B.2) Señala el tipo de estrofa y la rima que tiene el fragmento. ¿Crees que la rima ayuda a entender el texto? ¿Por qué?

C) Valoración y relación con el contexto literario

C.1) Los empeños de una casa sigue los presupuestos de la Comedia Nueva de Lope de Vega, ¿podrías señalar las características de este tipo de comedias? ¿Qué papel de los personajes de la Comedia Nueva piensas tú que desempeñaría doña Ana?

C.2) Indica otras autoras y autores de comedia de la época.

\subsection{Elena Garro}

\subsubsection{Enfoque metodológico}

Tal y como señala López Vega (2006), aunque la obra de Elena Garro no puede ser calificada como surrealista de manera absoluta, es evidente su ruptura con el costumbrismo y el realismo y la abundancia de temas y motivos propios del nuevo movimiento, como p ej., la fractura entre la realidad y la irrealidad o la alternancia de espacios y tiempos. Una obra de Elena Garro donde se ejemplifican claramente estos rasgos es Un hogar sólido (1958), cuya historia transcurre en una tumba y sus protagonistas están muertos. Esta singularidad, junto con la brevedad del texto y las semejanzas existentes con la exitosa película del cineasta español Alejandro Amenábar, Los Otros, hacen de este texto una lectura muy apropiada para el nivel de $4^{\circ}$ de la ESO, curso en cuyos objetivos y contenidos se incluyen los referidos al reconocimiento de los rasgos más significativos de la Literatura Moderna y Contemporánea. Asimismo, el texto resulta igualmente idóneo para trabajar algunos de los contenidos referidos al estudio de la lengua en este nivel, como son la variedad de registros, los procedimientos de formación de palabras o las relaciones léxico-semánticas. Finalmente, las referencias a la realidad mexicana en la obra de Garro, en general, y en el texto Un hogar sólido, en particular -como por ejemplo, oficial juarista, Chihuahua, Ricardo Bell o la Revolución- permiten realizar 
actividades de ampliación que posibilitarían profundizar en el conocimiento de aquella, e incluso vincularla, en su totalidad o de forma fragmentada, a otros niveles y asignaturas para trabajar muy distintos contenidos y competencias.

Por otra parte, dado que el Teatro Clásico y la Comedia Nueva son contenidos propios del tercer curso de la ESO y que además en el segundo ciclo de la ESO se incluyen objetivos y contenidos relacionados con los géneros periodísticos y los textos expositivo-argumentativos, consideramos que una reseña de la obra de Elena Garro, La Dama Boba, puede ser un texto idóneo para el desarrollo de competencias básicas del alumnado de $3^{\circ}$ de ESO.

\subsubsection{Información de la escritora}

\subsubsection{Ficha}

Apellidos: Garro

Nombre: Elena

Fecha de nacimiento: 12/12/1920

Fecha de defunción: 23/08/1998

Nacionalidad: Mexicana

\subsubsection{Reseña}

Narradora, poeta, periodista y dramaturga mexicana. Es considerada por algunos críticos como una de las precursoras del realismo mágico. Además en su obra los elementos subrealistas y político-sociales son una constante.

\subsubsection{Biografía}

Elena Garro, que nació en Puebla (México), era hija de madre mexicana y de padre español. Estudió en la Universidad Autónoma de Méjico, donde formó parte del grupo de teatro. En 1937 se casó con Octavio Paz, con quien tuvo una hija y del que se divorció en 1953. Por motivos políticos y personales en 1972 se marchó de México, a donde no regresó hasta 1994. Este autoexilio voluntario marca su obra, pues la mayor parte se crea antes o después de este. A la primera época, corresponde, por ejemplo, un volumen de obras de teatro de un solo acto, entre las que se encuentra, Un hogar sólido; mientras que Andamos huyendo, Lola marca el inicio de la segunda época.

En sus obras se hallan muchos temas y recursos propios del surrealismo, como por ejemplo, el sueño, la locura, la niñez, la alternancia de espacios y tiempos, etc. Estos rasgos se muestran con mayor claridad en tres de sus obras: una novela, Los recuerdos del porvenir; un cuento, La culpa es de los Tlaxcaltecas; y una obra de teatro, Un hogar sólido. Por otra parte, la mezcla de elementos fantásticos y maravillosos en las obras de Elena Garro hace que haya sido considerada por algunos críticos como una precursora del realismo mágico.

Murió en Cuernava en 1998.

3.2.2.4 Webgrafía:

Elena Garro, 
[http://cvc.cervantes.es/artes/ciudades_patrimonio/puebla/personalidades/garro.h tm, consulta 04/09/12]

Poniatowska, Elena (2006): "Una biografía de Elena Garro”, La Jornada Semanal [http://www.jornada.unam.mx/2006/09/17/sem-elena.html, consulta 04/09/12]

\subsubsection{Actividades}

3.2.3.1. ACTIVIDAD. LIBRO DE LECTURA. UN HOGAR SÓLIDO DE Elena Garro

NIVEL: $4^{\circ}$ ESO

BLOQUE DE CONTENIDOS: Educación Literaria- Teatro Moderno y Contemporáneo

BLOQUE DE CONTENIDOS: Conocimiento de la Lengua-Relaciones léxico semánticas

COMPETENCIAS BÁSICAS: 1. Competencia en comunicación lingüística; 4. Tratamiento de la información; 5. Competencia social y ciudadana; 6. Competencia cultural y artística; 7. Competencia para aprender a aprender

PROPUESTA DIDÁCTICA:

A) Lectura obligatoria del texto íntegro Un hogar sólido de Elena Garro

B) Comprensión global

B.1) Realiza un mural en el que se plasme el árbol genealógico de los personajes, sus características (nombre, edad, profesión, causa de muerte, nacionalidad, carácter, parentesco) y una breve biografía ${ }^{8}$.

C) Valoración y relación con el contexto literario

C.1) Justifica los rasgos que permitirían calificar la obra como teatro del absurdo y que a su vez la diferencian del costumbrismo o naturalismo.

D) Análisis de las formas de expresión

D.1) Define qué es un latinismo. Ejemplifica tu respuesta con el texto de Elena Garro, Un hogar sólido.

D.2) Señala algunas expresiones coloquiales que aparezcan en el texto de Elena Garro, Un hogar sólido.

D.3) Recopila los términos o expresiones relacionadas con el campo semántico de la muerte que aparezcan en el texto de Elena Garro, Un hogar sólido.

3.2.3.2. ACTIVIDAD. EL DIÁLOGO TEATRAL. Elena Garro

NIVEL: $2^{\circ}$ ESO

${ }^{8}$ Actividad propuesta en El texto dramático. En línea:

http://ilustreshabitantes.wikispaces.com/file/view/LITERATURA+II+UNIDADI.pdf, (28/10/2012). 
BLOQUE DE CONTENIDOS: Comunicación. El diálogo teatral.

COMPETENCIAS BÁSICAS: 1. Competencia en comunicación lingüística; 4. Tratamiento de la información; 5. Competencia social y ciudadana; 6. Competencia cultural y artística; 7. Competencia para aprender a aprender

PROPUESTA DIDÁCTICA:

1-Lee el siguiente diálogo teatral.

Vicente (atusándose el bigote). — No cabe duda. Alguien llega, tenemos huéspedes. (Canta):

Cuando en tinieblas

ríe la luna

y en la laguna

canta el alción...

Mamá Jesusita. — ¡Cállate, Vicente! No es hora de cantar. ¡Mira estos inoportunos! En mis tiempos la gente se anunciaba antes de caerle a uno de visita. Había más respeto. ¡A ver ahora a quién nos traen, a cualquier extraño de esos que se casaron con las niñas! ¡Abate Dios a los humildes!, como decía el pobre de Ramón, a quien Dios tenga en su santa gloria...

Vicente. — ¡Tú no cambiaste para bien, Jesusita! A todo le pones pero. Antes tan risueña que eras, lo único que te gustaba era bailar polcas (Tararea "Jesusita en Chihuahua" y hace unos pasos.) ¿ंTe acuerdas cómo bailamos en aquel Carnaval? (Sigue bailando.) Tu traje rosa giraba, giraba, y tu cuello estaba muy cerca de mi boca...

Jesusita. — ¡Por Dios, primo Vicente! No me recuerdes esas tonterías.

Garro, Elena (1958): Un hogar sólido.

\section{A) Análisis de la forma}

Después de leer el fragmento dramático contesta las siguientes cuestiones:

A.1) ¿Se trata de un monólogo o de un diálogo? ¿Por qué?

A.2) Señala alguna de las acotaciones que aparecen el texto.

A.3) Desde el punto de vista formal, ¿cómo se distinguen las acotaciones del resto de la parte dialogada?

A.4) ¿Qué expresan las acotaciones?

B) Expresión

B.1) Siguiendo la fórmula del diálogo teatral, continúa la escena. Después puedes comprobar si tu texto se parece al que escribió Elena Garro.

\subsubsection{ACTIVIDAD. METÁFORAS Y FIGURAS. UN HOGAR SÓLIDO DE}

\section{Elena Garro}

NIVEL: $2^{\circ}$ ESO.

BLOQUE DE CONTENIDO: Educación literaria: Figuras retóricas, metáforas y comparaciones

COMPETENCIAS BÁSICAS: 1. Competencia en comunicación lingüística; 4. Tratamiento de la información; 6. Competencia cultural y artística

PROPUESTA DIDÁCTICA: 
1-Lee con atención el siguiente texto

MAmÁ JEsusita. - ¡Catita! Ven acá y púleme la frente; quiero que brille como la Estrella Polar. Dichoso el tiempo en que yo corría por la casa como una centella, barriendo, sacudiendo el polvo que caía sobre el piano en engañosos torrentes de oro, para luego cuando ya cada cosa relucía como un cometa, romper el hielo de mis cubetas dejadas al sereno, y bañarme con el agua cuajada de estrellas de invierno. ¿Te acuerdas, Gertrudis? Eso era vivir; rodeada de mis niños tiesos y limpios tomo pizarrines.

Garro, Elena (1958): Un hogar sólido.

A) Comprensión léxica

A.1) Busca un sinónimo en el texto para los siguientes términos:

Rayo:

Llena:

Rectos:

A.2) Busca en el texto los términos que se definen a continuación

Corriente o avenida impetuosa de aguas que sobreviene en tiempos de muchas lluvias o de rápidos deshielos.

A la intemperie de la noche.

Barrita de lápiz o de pizarra no muy dura, generalmente cilíndrica, que se usa para escribir o dibujar en las pizarras de piedra.

B. Análisis de las formas de expresión: la metáfora y la comparación

B.1) En el texto aparecen algunas figuras retóricas, como por ejemplo, metáforas y comparaciones o símiles. Señala las comparaciones y metáforas que aparecen en el fragmento.

B.2) Tanto en las metáforas como en las comparaciones se establece una relación de semejanza entre dos términos. Explica la base de las comparaciones y metáforas que aparecen en el texto. Por ejemplo, Brille como la estrella Polar: la Estrella Polar es una de las estrellas más brillantes, luego la frase en el texto significa que quiere que la frente brille mucho.

\subsubsection{ACTIVIDAD. RESEÑA TEATRAL DE LA DAMA BOBA DE Elena} Garro

NIVEL: $3^{\circ}$ ESO

BLOQUE DE CONTENIDOS: Comunicación. Redacción de opiniones: La reseña

COMPETENCIAS BÁSICAS: 1. Competencia en comunicación lingüística; 4. Tratamiento de la información; 5. Competencia social y ciudadana; 6. Competencia cultural y artística; 7. Competencia para aprender a aprender

PROPUESTA DIDÁCTICA:

1-Lee con atención el siguiente texto

La Dama Boba de Elena Garro, es la historia de un grupo de actores que viajan de pueblo en pueblo llevando la representación de la obra homónima y original de Lope de Vega, cuando Francisco, uno de los actores principales se pierde y es acogido en Tepan, comunidad en la que Don Salvador, el presidente municipal, lo 
obliga a ser maestro del pueblo, ya que lo vio personificando al profesor de la mencionada obra.

Se trata de un proyecto de talentosos jóvenes actores que tienen como mensaje primordial en esta obra la denuncia de la vida en las comunidades rurales, presentando personajes nada alejados de la realidad, del cacique del pueblo, la arrogante mujer de la ciudad, la inocencia encarnada en una mujer de pueblo, el primer amor, la idealización de las personas que viven en grandes urbes, los deseos de aprender, entre otras lecciones que en este montaje cómico toman fuerza y cautivan al espectador.

De igual forma se hace una crítica directa a la falta de compromiso de la clase considerada intelectual, que no se inmuta a hacer algo por los desfavorecidos; la representación se apoya principalmente en la actuación de los protagonistas no necesitando nada más que el escenario y la convicción de cada uno de los personajes, que sumergen a los asistentes en la dinámica de vida de Tepan, que simboliza a uno de los miles de pueblos olvidados, de los que coloquialmente se dice "por lo que no pasó Dios".

A lo largo de una hora 20 minutos, Francisco (Iñigo Gutiérrez) logrará abrir su visión del mundo a otro en el que Lupe (Maggi Briz), una mujer piel de canela e inteligencia aguda e hija del alcalde Don Salvador (Moisés Rivera), se ganará su corazón, venciendo a su amor del pasado, una cosmopolita mujer de la capital llamada Sara (Tania Moctezuma).

La dirección corre por parte de la actriz Laura "Lala" Fernández, quien llevó el imaginario de Elena Garro a un contexto que no deja de ser actual y relevante; y que a la vez ofrece un rato de buen humor y entretenimiento dentro de la rama del teatro alternativo.

Esta puesta en escena se presentará hasta el día viernes en el Auditorio Manuel Acévez de la Universidad Iberoamericana, teniendo funciones este día a las 18:00 y 20:00 horas, mañana se presenta a las 20:00 horas y el viernes a las 9:00 y 18:00 horas; el 3 de diciembre tendrá una función especial en la Sala de las Artes Escénicas en el Ágora de la Universidad de las Américas Puebla a las 19:00 horas, la entrada es libre.

“La Dama Boba”, El Sol de Puebla [http://www.oem.com.mx/laprensa/notas/n1416892.htm, consulta 05/09/2012]

A) Comprensión léxica

A.1) Busca en el texto un sinónimo para los siguientes términos y expresiones:

Representada:

Ciudad:

Conmueve:

A.2) Busca en el texto los términos a los que se refieren las siguientes definiciones:

Dicho de dos o más personas o cosas: Que llevan un mismo nombre.

Dicho de una persona: Que tiene este ingenio.

Persona que en una colectividad o grupo ejerce un poder abusivo: 
A.3) Un eufemismo es una palabra o expresión que se utiliza para sustituir a otra que se considera malsonante o tabú. Señala el eufemismo que aparece en el texto. ¿Cuál es el término que trata de evitarse?

B) Comprensión global

B.1) ¿Por qué Don Salvador obliga a Francisco a ser el maestro del pueblo?

B.2) ¿Dónde se sitúa la obra de Elena Garro la Dama Boba?

B.3) ¿Qué realidad refleja la obra?

C) Interpretación y producción de textos

C.1) El texto que acabamos de leer es una reseña de la representación teatral de una obra de Elena Garro. En la reseña podemos encontrar la siguiente información: contenido argumental de la obra, interpretación de la obra y datos de la representación. Señala en el texto donde aparece esta información.

C.2) Ahora escribe tú una reseña sobre la representación de la Dama Boba de Lope de Vega.

\section{CONCLUSIÓN}

La exclusión de las escritoras del canon literario escolar no solo representa una importante pérdida para la literatura, sino que constituye un falseamiento de esa tradición literaria, al no dar cuenta de la cantidad y variedad de voces femeninas (López-Navajas y López García, 2012) que de forma ininterrumpida han construido la literatura que nos pertenece a todos. Y eso constituye un fracaso cultural de envergadura, porque nos priva de buena parte de nuestros referentes y que además afecta directamente a la calidad de la educación.

Por añadidura, para las mujeres tiene más implicaciones, pues al no verse reconocidos sus logros y perder modelos de identificación, su posición social se vuelve secundaria (ellas parecen no haber sido capaces de contribuir de forma relevante a la tradición literaria y cultural). Es un mecanismo de discriminación -el no aparecer en los textos- que sigue vigente, hurtándoles autoridad y reconocimiento a las mujeres, y lo perpetuamos desde la educación obligatoria, que alcanza a toda la ciudadanía, a la que transmite estos valores de minusvaloración y desautorización femenina. Desde la educación mismo, a través de esa visión de mundo sin mujeres, asentamos patrones sociales de desigualdad. Cuando nuestra finalidad debe ser acabar con ellos.

Por todo ello se hace necesario y urgente revertir esta situación. La tarea de incluir a las escritoras (y también a las artistas y las científicas y tecnólogas y las músicas y todas aquellas cuyas acciones han sido remarcables) dentro de los contenidos que se trabajan en el aula se vuelve imprescindible. Y también de cambiar los parámetros, las categorías, la periodización y el propio relato de la historia, que las debe incluir. Pero el primer paso es empezar a tenerlas presentes. Por eso las actividades aquí propuestas pretenden mostrar algunas de las maneras de incluirlas. El trabajo con textos resulta un modelo adaptable, sencillo y eficaz 
para poder trabajar en clase y con cualquier otra autora. De eso se trata, porque es desde el aula desde donde nacen los cambios.

\section{BIBLIOGRAFÍA}

ALIC, Margaret (1991), El legado de Hipatia, Méjico, Siglo Veintiuno Editores.

ÁLVAREZ CAÑIBANO, Antonio (coord.) (2008), Compositoras españolas: La creación musical femenina desde la Edad Media hasta la actualidad, Madrid, Centro de Documentación de Música y Danza, INAEM.

ÁLVAREZ, Mari; NUÑO, Teresa; y SOLSONA, Nuria (2003), Las científicas y su historia en el aula, Madrid, SíntesisBLANCO GARCÍA, Nieves (2004), "El saber de las mujeres en la educación”, XXI Revista de Educación, 6: 43-53

COLL MIRABENT, Isabel (2001), Diccionario de mujeres pintoras de la España del siglo XIX, Barcelona, El Centaure Groc.

COMUNIDAD VALENCIANA. DECRETO 112/2007. Diari Oficial de la Generalitat Valenciana, 24 de julio de 2007, nº 5562, p. 30402-30587.

ESPIGADO TOCINO, Gloria (2004), "Historia y genealogía a través de los libros de texto", La ausencia de las mujeres en los contenidos escolares, Carmen Rodríguez (coord.), Buenos Aires, Miño y Dávila: 113-144.

ESPAÑA. REAL DECRETO 1631/ 2006. Boletín Oficial del Estado, 5 de enero de 2007, n'5, p. 677-773.

FIGUEIRAS, Lourdes et al. (1998), Género y Matemáticas, Madrid, Síntesis

GARRETA, Nuria y CAREAGA, Pilar (1987), Modelos masculinos y femeninos en los textos de EGB, Madrid, Instituto de la Mujer.

GREER, Germaine (2005), La carrera de obstáculos. Vida y obra de las pintoras antes de 1950, Madrid, Bercimuel.

GUTIÉRREZ, Luzelena y PRADO, Gloria M. (eds.) (2006), Elena Garro: Recuerdo y porvenir de una escritura, México, Universidad Iberoamericana.

HERAS I TRIAS, Pilar (1987), "El papel de la mujer en la enseñanza y en los libros de texto en Catalunya", La investigación en España sobre mujer y educación, Amparo Moreno et al., Madrid, Instituto de la Mujer.

JAMES, R. (2004), New Historical Anthology of Music by Women, Indiana, Indiana University Press.ALLÉ, Anna (2004), La vida escrita por las mujeres, Barcelona, Lumen.

LEÓN VEGA, Margarita (2006), "La realidad está en otra parte. El surrealismo en la obra de Elena Garro”, Elena Garro: Recuerdo y porvenir de una escritura, GUTIÉRREZ, Luzelena y PRADO, Gloria M. (eds.), Méjico, Universidad Iberoamericana: 25-42.

LOMAS, Carlos (2002), "El sexismo en los libros de texto", Mujer y educación: educar para la igualdad, educar desde la diferencia, GONZÁLEZ, Ana y LOMAS, Carlos (coords.), Barcelona, Graó: 193-222. 
LÓPEZ-NAVAJAS, Ana (2014), “Análisis de la ausencia de las mujeres en los manuales de la ESO: una genealogía del conocimiento ocultada”, Revista de Educación, 363. Enero-abril 2014. DOI: 10.4438/1988-592X-RE-2012-363-188

LÓPEZ-NAVAJAS, Ana y Querol, María (2012), “¿Están presentes las escritoras en la enseñanza de la literatura en la ESO?”, España y América en el Bicentenario de las Independencias, CASAJÚS, Lucía y FERNÁNDEZ BELTRÁN, Francisco José (eds.), Castellón de la Plana, Universitat Jaume I: 455-472.

LÓPEZ-NAVAJAS, Ana y LÓPEZ GARCÍA-MOLINS, Ángel (2012) “El desconocimiento de la tradición literaria femenina y su repercusión en la falta de autoridad social de las mujeres" Quaderns de Filologia Estudis literaria. Vol XVII, $27-40$

[http://roderic.uv.es/bitstream/handle/10550/31668/27.pdf?sequence=1]

LORENZO ARRIBAS, Josemi (2008), "Una historia poco canónica de la música hispánica hasta 1557”, Compositoras españolas. La creación musical femenina desde la Edad Media hasta la actualidad, Madrid, Centro de Documentación de Música y Danza: 3-42.

MARTINO, Giulio de y BRUZZESE, Marina (1994), Las filósofas, Madrid, Cátedra.

MAYAYO, Patricia (2003), Historias de mujeres, historias de arte, Madrid, Cátedra.

MONTEJO GURRUCHAGA, Lucía y BARANDA LETURIO, Nieves (2002), Las mujeres escritoras en la historia de la Literatura Española, Madrid, UNED Ediciones.

MUÑOZ LÓPEZ, Ma Pilar (2004), Mujeres españolas en las artes plásticas, Madrid, Editorial Síntesis.

RODRÍGUEZ MARTÍNEZ, Carmen (coord.) (2004), La ausencia de las mujeres en los contenidos escolares, Buenos Aires, Miño y Dávila.

ROSSELLÓ, Isabel (1998), Música, femení singular. Illes Balears, Di7 edició.

SADIE, Julie Anne y SAMUEL, Rhian (1994), The New Grove Dictionary of Women Composers, London and Basingstoke, Macmillan Press.

SERRANO Y SANZ, Manuel (1975 [1898]), Apuntes para una biblioteca de escritoras españolas desde el año 1401 al 1833, Madrid, Biblioteca de Autores Españoles.

SUBIRATS, Marina (coord.) (1993), El sexismo en los libros de texto: análisis y propuesta de un sistema de indicadores, Madrid, Instituto de la Mujer, Serie Estudios, $\mathrm{n}^{\circ} 37$.

ZAVALA, Iris M.; DÍAZ-DIOCARETZ, Myriam. (1993-2000), Breve historia feminista de la literatura española (en lengua castellana), Barcelona, Anthropos, 6 vol. 
MONTEJO GURRUCHAGA, Lucía y BARANDA LETURIO, Nieves (2002), Las mujeres escritoras en la historia de la Literatura Española, Madrid, UNED Ediciones.

MUÑOZ LÓPEZ, Ma Pilar (2004), Mujeres españolas en las artes plásticas, Madrid, Editorial Síntesis.

RODRÍGUEZ MARTÍNEZ, Carmen (coord.) (2004), La ausencia de las mujeres en los contenidos escolares, Buenos Aires, Miño y Dávila.

ROSSELLÓ, Isabel (1998), Música, femeni singular. Illes Balears, Di7 edició.

SADIE, Julie Anne y SAMUEL, Rhian (1994), The New Grove Dictionary of Women Composers, London and Basingstoke, Macmillan Press.

SERRANO Y SANZ, Manuel (1975 [1898]), Apuntes para una biblioteca de escritoras españolas desde el año 1401 al 1833, Madrid, Biblioteca de Autores Españoles.

SUBIRATS, Marina (coord.) (1993), El sexismo en los libros de texto: análisis y propuesta de un sistema de indicadores, Madrid, Instituto de la Mujer, Serie Estudios, $\mathrm{n}^{\circ} 37$.

ZAVALA, Iris M.; DÍAZ-DIOCARETZ, Myriam. (1993-2000), Breve historia feminista de la literatura española (en lengua castellana), Barcelona, Anthropos, 6 vol. 